\title{
Chemical nature of catalysts of oxide nanoparticles in environment prevailing during growth of carbon nanostructures by CCVD
}

\author{
M JANA $^{1, *}$, A SIL ${ }^{1}$ and S RAY ${ }^{1,2}$ \\ ${ }^{1}$ Department of Metallurgical and Materials Engineering, Indian Institute of Technology Roorkee, Roorkee 247 667, India \\ ${ }^{2}$ School of Engineering, Indian Institute of Technology Mandi, Mandi 175001, India
}

MS received 20 January 2016; accepted 29 April 2016

\begin{abstract}
Carbon nanostructures (CNS) are often grown using oxide nanoparticles as catalyst in chemical vapour deposition and these oxides are not expected to survive as such during growth. In the present study, the catalysts of cobalt- and nickel oxide-based nanoparticles of sizes varying over a range have been reduced at $575^{\circ} \mathrm{C}$ under environment resulting from the introduction of $\mathrm{C}_{2} \mathrm{H}_{2}+\mathrm{NH}_{3}$ during growth of $\mathrm{CNS}$ as well as under introduction of $\mathrm{C}_{2} \mathrm{H}_{2}$ and $\mathrm{NH}_{3}$ separately. The structure of the reduced nanoparticles is often different from the equilibrium structure of the bulk. Nanoparticles of cobalt oxide with and without doping by copper oxide are reduced to cobalt alloy or cobalt nanoparticles having fcc structure, but the rate of reduction is relatively less in $\mathrm{NH}_{3}$ environment. However, reduced nickel oxide nanoparticles with and without doping shows a mix of fcc and hep phases. The presence of hydrogen and nitrogen in the environment appears to discourage the formation of hcp nickel as inferred from the results in $\mathrm{NH}_{3}$ environment. Cobalt carbide forms when the $10 \mathrm{wt} \%$ or less doped cobalt oxide is reduced in $\mathrm{C}_{2} \mathrm{H}_{2}+\mathrm{NH}_{3}$ environment. At higher level of doping of $20 \mathrm{wt}$ \% , separate metallic phase of copper appears and carbide formation gets suppressed.
\end{abstract}

Keywords. Catalyst; oxide nanoparticle; carbon nanostructure; catalytic chemical vapour deposition; reduction.

\section{Introduction}

Nanoparticles of oxides of transition metals like cobalt and nickel have been used as catalyst in the reducing environment, prevailing in the chamber of catalytic chemical vapour deposition (CCVD) during growth of carbon nanostructures (CNS) [1]. Baker et al [2] while using iron oxide as catalyst claimed that $\mathrm{FeO}$ appears to be a much better catalyst than metallic iron for the formation of filamentary carbon. Recently, Rummeli et al [3] also have shown the ability of various pure oxides to grow graphitic sheets under typical CVD conditions for CNS synthesis, which contradicts the results of Hofmann et al [4], which claims that the formation of graphitic network is not possible on oxidized iron. Apart from the reducing environment of decomposed hydrocarbon vapour or gas existing during the growth of CNS by CCVD, the oxide catalysts are often subjected to pre-treatment in reducing environment containing hydrogen, and this step may also cause reduction of oxides to metals by hydrogen [5]. It has been confirmed by the studies on reduction of oxide particles by hydrogen [6]. Richardson et al [7], who studied $\mathrm{NiO}$ reduction using in situ X-ray diffraction (XRD), described the reduction to proceed as follows: (i) dissociation of $\mathrm{H}_{2}$ on two $\mathrm{Ni}$ atoms surrounding an oxygen vacancy [8]; (ii) diffusion of adsorbed $\mathrm{H}$ atoms to

*Author for correspondence (malay.jana@gmail.com)
$\mathrm{NiO}$ reaction centres; (iii) rupture of $\mathrm{Ni}-\mathrm{O}$ bonds and desorption of $\mathrm{H}_{2} \mathrm{O}$; (iv) nucleation and growth of Ni clusters; (v) dissociation of $\mathrm{H}_{2}$ on the metallic clusters once their size is sufficient; and (vi) enhancement of the reaction rate as the metal clusters grow into $\mathrm{Ni}$ crystallites. Activation energy for $\mathrm{NiO}$ reduction using $\mathrm{H}_{2}$ varies over an order of magnitude from 10 to $150 \mathrm{~kJ} \mathrm{~mol}^{-1}$ [7]. Since the environment during growth of CNS is highly reducing due to decomposition of carbon-bearing gas, it is likely that oxides of cobalt or nickel may not survive as such to act as catalyst and these nanoparticles get reduced to metals, which are well known for catalysing the growth of CNS, actually play the role of catalyst. Hernadi et al [9] also considered that prior reduction pre-treatment of iron oxide is not necessary since the hydrocarbon atmosphere reduces it under prevailing conditions during growth of CNS.

It has been claimed by some researcher that metal as such does not act as a catalyst and there is need for formation of metal carbide, which decomposes to supply carbon for the growth of CNS [10,11]. Ni et al [12] have, therefore, claimed that the formation of CNS requires temperatures higher than the decomposition temperature of the relevant metal carbide. In general, transition metals, which are widely used as catalyst for growth of CNS, have vacancies in the d-electron orbital and with increasing d-electron vacancies they show increasing affinity for carbon. Metals without any vacancy in d-shells like $\mathrm{Zn}$ or $\mathrm{Cu}$ have little affinity for carbon. 
Metals with a few vacancies in d-shell, like Ni, $\mathrm{Fe}$ and $\mathrm{Co}$, exhibit finite solubility of carbon and formation of metastable carbides, while transition metals with many d-vacancies like $\mathrm{Ti}$ and Mo have very high affinity for carbon so as to form strong carbides [13-15]. Since the transition metals used as a conventional catalyst for the CNS growth are carbide formers, there could be a role of carbides. Wirth and others [16] proposed that pure metal is the active catalyst, while metal carbides have sometimes been detected in experiments especially involving iron catalyst nanoparticles [11,17]. However, the catalytic activity of these metal carbides has not been confirmed even for dissociation of hydrocarbon. On the basis of free energy, it is observed that acetylene, ethylene and ethanol are less stable than graphite at all temperatures under atmospheric pressure and under sufficient activation, these compounds may self-decompose into carbon, di-hydrogen and a large variety of volatile organic compounds and polycyclic aromatic hydrocarbons [18-21]. Sharma et al [22] believe that metastable phase of carbide may form under a dynamic equilibrium for the following reaction $3 \mathrm{Ni}+\mathrm{C} \leftrightarrow \mathrm{Ni}_{3} \mathrm{C}$, where the continuous flux of carbon, generated by decomposition of $\mathrm{C}_{2} \mathrm{H}_{2}$, favours the formation of $\mathrm{Ni}_{3} \mathrm{C}$ while high temperature $\left(>520^{\circ} \mathrm{C}\right)$ favours its decomposition. Confusion often persists because lattice constants of pure metal and their carbides are sometimes very close. Takagi et al [23] have used noncarbide-forming catalysts like gold, silver and copper to grow CNS by CCVD. Thus, the formation of carbide could not be an essential pre-requisite for the growth of CNS.

In our earlier studies $[21,24]$ it was observed that melting of oxide nanoparticles and their reduction to metallic state takes place in the reducing environment, resulting from incoming $\mathrm{NH}_{3}$ and $\mathrm{C}_{2} \mathrm{H}_{2}$ used by us in the chamber of CCVD during growth of carbon nanostructures. So it was inferred that the oxide nanoparticles as such do not act as catalyst for the growth of CNS, but the reduced metal acts as the catalyst. There are a very few reports available on the structure of phases of catalysts responsible for catalytic growth of CNS [25-30]. There are different parameters including the size of the nanoparticles which are reported to determine the structure of the metallic phase [18,30-32], but there are often contradictory results. The present study investigates the reduction behaviour of nanoparticles of cobalt and nickel oxides with and without doping by copper oxide under $\mathrm{C}_{2} \mathrm{H}_{2}+\mathrm{NH}_{3}$ environment prevailing during growth of CNS as well as under $\mathrm{C}_{2} \mathrm{H}_{2}$ and $\mathrm{NH}_{3}$ individually. The nature of reduced phases and their structure have been determined.

\section{Experimental}

\subsection{Preparation of oxide nanoparticles}

Oxide nanoparticles of cobalt and nickel as such and doped with copper oxide were prepared by aqueous sol-gel route using cobalt (II) acetate tetra-hydrate (Merck), nickel acetate tetra-hydrate (Merck) and copper (II) sulphate 5-hydrate (Merck), respectively, as sources of cobalt, nickel and copper. The copper percentage was varied from 0 to $20 \mathrm{wt} . \%$ substitution of cobalt/nickel by copper in the aqueous saturated solution of both the metal salts and then mixed with chelating agent of citric acid monohydrate (Merck), followed by slow stirring at a gelation temperature ranging from 72 to $84^{\circ} \mathrm{C}$ until the formation of a gel. The gels were dried overnight at $120^{\circ} \mathrm{C}$ in an oven. The dried samples were ground to powders after calcination in air for $5 \mathrm{~h}$ at a temperature varying from 310 to $800^{\circ} \mathrm{C}$ so as to get a narrow size range of particles. The designation of oxide nanoparticles used here starts with the metallic elements of oxide including dopant, like $\mathrm{Co}$ or $\mathrm{CoCu}$ and $\mathrm{Ni}$ or $\mathrm{NiCu}$, followed by the extent of doping, when applicable, indicated by wt.\% of copper replacing cobalt/nickel in their oxides.

\subsection{Reduction of oxide nanoparticles in different reducing environment}

In the present study, three types of reducing environments have been used: (a) $\mathrm{NH}_{3}+\mathrm{C}_{2} \mathrm{H}_{2}$ to simulate the environment prevailing during growth of carbon nanostructures, and individual constituents of (b) $\mathrm{C}_{2} \mathrm{H}_{2}$ and (c) $\mathrm{NH}_{3}$ to determine their role in the process of reduction.

The oxide nanoparticles, prepared following steps outlined in subsection 2.1, were spread over the alumina boat. The boat containing oxide nanoparticles was placed in a horizontal tubular furnace and heated to a temperature of $525^{\circ} \mathrm{C}$. $\mathrm{NH}_{3}$ gas was introduced into the furnace at a rate of about $60 \mathrm{sccm}$ under atmospheric pressure. The temperature of the furnace was then increased to $575^{\circ} \mathrm{C}$ and $\mathrm{C}_{2} \mathrm{H}_{2}$ gas was introduced along with flowing $\mathrm{NH}_{3}$ gas for about 3 min to avoid significant formation of CNS, masking the results of reduction. The flow rate of $\mathrm{C}_{2} \mathrm{H}_{2}$ gas was controlled at $10 \mathrm{sccm}$ in total flow rate of $70 \mathrm{sccm}$.

To check the reduction behaviour of oxide nanoparticles in $\mathrm{C}_{2} \mathrm{H}_{2}$ and $\mathrm{NH}_{3}$ environments individually, after placing the boat containing the oxide nanoparticles, the individual gas was introduced at $525^{\circ} \mathrm{C}$ at a flow rate of about $60 \mathrm{sccm}$ and after reaching $575^{\circ} \mathrm{C}$ the flow rate was adjusted to $10 \mathrm{sccm}$ for about $3 \mathrm{~min}$.

\subsection{Characterization}

The morphology of the oxide nanoparticles after reduction was observed by transmission electron microscopy (TEM), and elemental analyses of catalyst particles inside the CNS were conducted with JEOL-2100, FEI Tecnai $\mathrm{G}^{2}$ 20, FEI Tecnai F20-G2 FEGTEM and JEOL 200CX TEM at an operating voltage of $200 \mathrm{kV}$. XRD studies were carried out using X-ray diffractometer (Bruker AXS, D8 advance) with $\mathrm{CuK}_{\alpha}$ radiation (1.541 $\AA$ ). The sizes of the nanoparticles were measured using 'Image J' software on FESEM (FEI QUANTA 200 F) micrographs and compared with the results of particle size analyser 'Zetasizer' (MALVERN Instrument, Nano-ZS90). 


\section{Results and discussion}

The experiments on reduction have been carried out in the broader context of growth of carbon nanostructure using catalysts of oxide nanoparticles of cobalt and nickel with and without doping by copper oxide, which are reported earlier $[21,24]$. These oxides may have undergone chemical change during growth of CNS in the chamber of CCVD set-up in the presence of reducing atmosphere of carbon-bearing gas and carrier gas of acetylene and ammonia, respectively.

\subsection{Change in chemical nature of oxide catalysts}

The chemical changes taking place in the catalysts of oxide nanoparticles after exposure to reducing environment at elevated temperatures have been examined by XRD analysis and these results have been supplemented by the results of direct examination of the catalyst particles embedded inside CNS under TEM/scanning TEM along with energy dispersive spectrum (EDS) as well as selected area diffraction (SAD) pattern.

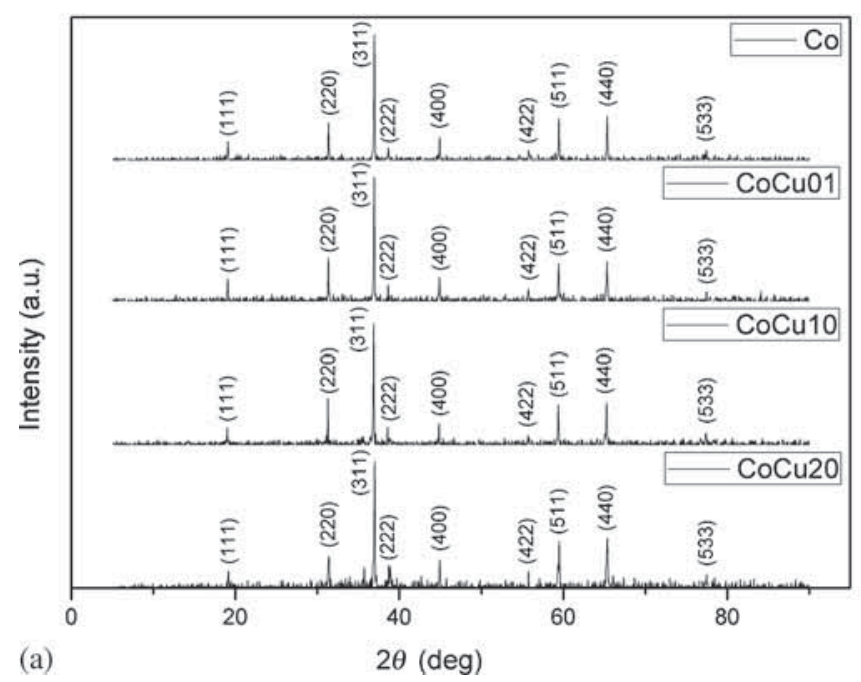

XRD pattern of pure cobalt oxide nanoparticles shown in figure 1a reveals only cubic phase of spinel $\mathrm{Co}_{3} \mathrm{O}_{4}$ with a lattice parameter of $8.065 \AA$. Doping results in replacement of divalent cobalt by copper resulting in $\mathrm{Co}_{3-x} \mathrm{Cu}_{x} \mathrm{O}_{4}$ with an increase in lattice parameter to $8.084 \AA$. The crystal structure remains cubic on doping as observed from XRD patterns of doped oxides in figure 1a and the structure has a space group ( $F d-3 m ; 227)$.

The XRD patterns of cobalt-based oxide nanoparticles after exposure to reducing environment show that the oxides get reduced to cobalt bearing fcc phase $(F m-3 m ; 225)$ with lattice parameter of $3.544 \AA$ and there is no significant presence of a separate phase of reduced metallic copper, for doping up to $10 \mathrm{wt} . \%$ as revealed in figure $1 \mathrm{~b}$. Bulk cobalt is stable in its hexagonal phase at room temperature, but fcc phase appears as stacking faults indicating small difference in energy between fcc and hcp phases [33]. Therefore, it is not surprising that fcc cobalt is observed in nanoparticles as they have higher energy than that of bulk. There is presence of carbide phase of $\mathrm{Co}_{2} \mathrm{C}$ in reduced cobalt oxide doped at $10 \mathrm{wt} . \%$ as indicated in XRD pattern, although there is no such carbide present in reduced pure cobalt oxide.

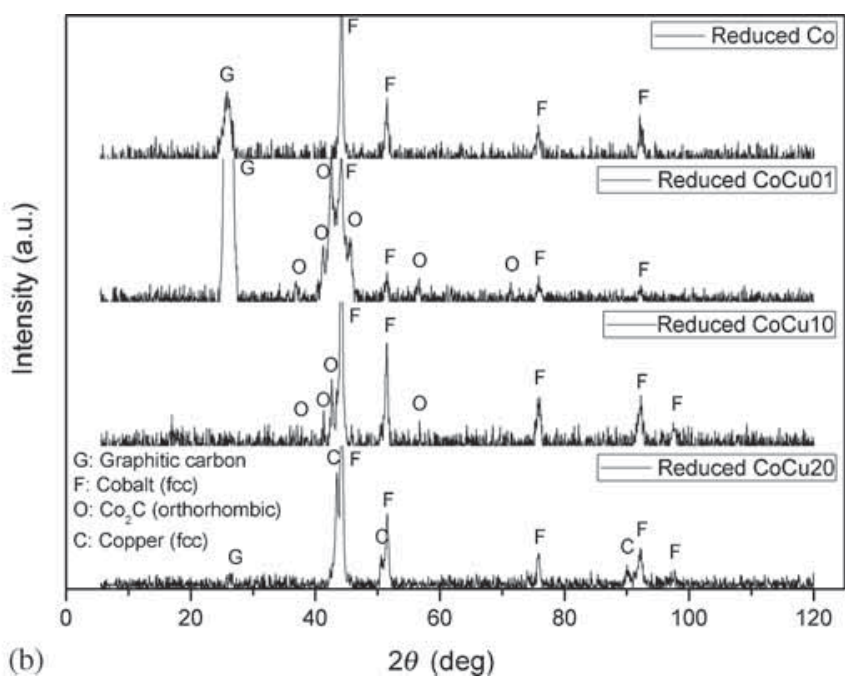
$2 \theta(\mathrm{deg})$

Figure 1. XRD patterns showing the phases obtained (a) before and (b) after exposure of cobalt oxide-based nanoparticles to reducing environment prevailing during the growth of CNS.
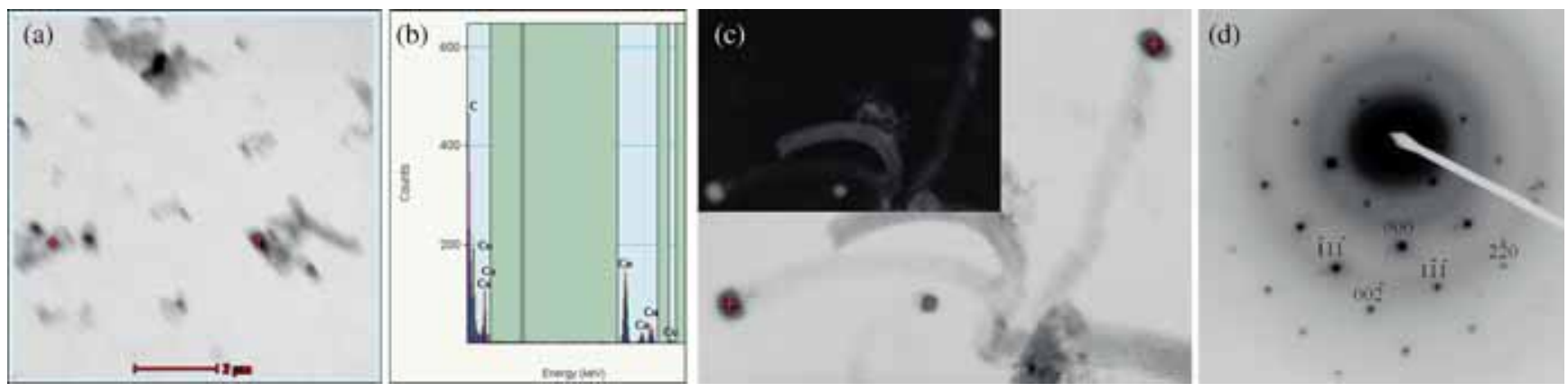

Figure 2. (a) STEM image of nanoparticles inside CNS grown using cobalt oxide, (b) EDS spectrum taken on the cross points indicated in a, (c) bright and dark (inset) field TEM image of CNS containing catalyst nanoparticles, and (d) selected area diffraction (SAD) of catalyst nanoparticle inside CNS as shown by cross point in c, with spots belonging to fcc cobalt and rings to the graphitic carbon. 
However, at increased doping of $20 \mathrm{wt} . \%$ carbide formation is suppressed. Although cobalt has a very low bulk solubility $(<0.48 \mathrm{wt} . \%)$ for copper [34], there is no presence of separate phase of metallic copper till $20 \mathrm{wt} . \%$ of doping. Thus it appears that solubility limit gets extended in nanoparticles as it has been observed for $\mathrm{Pb}-\mathrm{Sn}, \mathrm{Co}-\mathrm{ZnO}$ or $\mathrm{C}-\mathrm{Cu}$ systems [35-37].

The nanoparticles located inside CNS synthesized using pure cobalt oxide $\left(\mathrm{Co}_{3} \mathrm{O}_{4}\right)$ have been examined under TEM, to confirm the phases of the catalyst after growth of CNS and the results are shown in figure 2. It has been observed that the oxide nanoparticles of cobalt have been reduced to pure metallic fcc cobalt as indicated by its SAD pattern (figure 2d). The copper peaks observed in EDS spectrum of figure $2 \mathrm{~b}$ is due to the copper grid used as sample holder in TEM study. The dark field image inset in figure $2 \mathrm{c}$ confirmed that the point used to get the SAD pattern is from the catalyst nanoparticle inside CNS. Thus, the results of reduction during growth of CNS are similar to those observed under simulated environment.

Figure 3a shows XRD patterns of the pure and doped nickel oxide nanoparticles. Pure nickel oxide (NiO) has only cubic phase with a lattice parameter of $4.176 \AA$ and the structure remains cubic even after doping, belonging to space group $(F m-3 m ; 225)$ but lattice parameter increases to $4.188 \AA$. Figure $3 \mathrm{~b}$ shows XRD patterns of the reduced nanoparticles of pure nickel oxide and those with doping up to $20 \mathrm{wt}$. $\%$ of copper.

Pure nickel oxide nanoparticles reduce to both cubic (Fm$3 m ; 225)$ and hexagonal $(P 63 / m m c ; 194)$ phases of metallic nickel. It may be noted that at room temperature cubic nickel is the stable phase of bulk nickel and not the hcp phase. But nickel oxide doped with 10 wt.\% of copper as in $\mathrm{NiCu} 10$ gets reduced to more of fcc phase and less of hcp phase compared to that for reduced pure $\mathrm{NiO}$. Interestingly, increase in doping up to 15 or $20 \mathrm{wt} \%$ when copper is expected to enter into the lattice of nickel, it appears that there is increase in the amount of hcp phase along with some cubic nitride of nickel. However, there appears to be split in peaks of fcc nickel solid solution marked ' $\mathrm{f}$ ' in XRD of NiCu10, which could be due to different lattice parameters of solid solution caused by variation of copper content in different locations. If there is any carbide it could not be distinctly identified as all the peaks corresponding to the carbide of nickel $\left(\mathrm{Ni}_{3} \mathrm{C}\right)$ overlap with the peaks corresponding to nickel. It is reported that hcp nickel formation involves the formation of $\mathrm{Ni}_{3} \mathrm{C}$ via martensitic transformation [18]. Pearson has observed that although nickel with an fcc structure is more stable than hcp nickel under ambient conditions, hcp nickel could be induced by hydride, nitride and carbide formation [19]. There is presence of hydrogen, nitrogen and carbon in the reaction chamber of CCVD due to decomposition of ammonia and carbonbearing gas introduced there. Table 1 summarizes the details of the oxide nanoparticles used and the phases detected.

The lattice parameter of fcc phase after reduction increases from 3.524 to $3.624 \AA$ with increase in doping. Similarly, peak positions of hcp phase have similarly changed with increase in doping. It may be indicative of more copper going into the lattice of both fcc and hcp nickel with increase in doping, resulting in $\mathrm{NiCu}$ alloy upon reduction. However, there is no increase in lattice parameter of fcc cobalt with increase in doping, possibly due to limited solubility of copper in cobalt. It may be remembered that some change in lattice parameter is also expected due to deviation of lattice positions in nanoparticles compared to those in equilibrium bulk metal or alloy, particularly near the surface region of nanoparticles.

Cobalt could exist in either hexagonal-closed-packed (hcp: $\alpha$ ) or face-centered-cubic (fcc: $\beta$ ) phases. The hcp phase in bulk cobalt is stable at room temperature while it transforms into fcc phase above $450^{\circ} \mathrm{C}$. However, in nanoparticles of cobalt reduced from pure cobalt oxide one observes
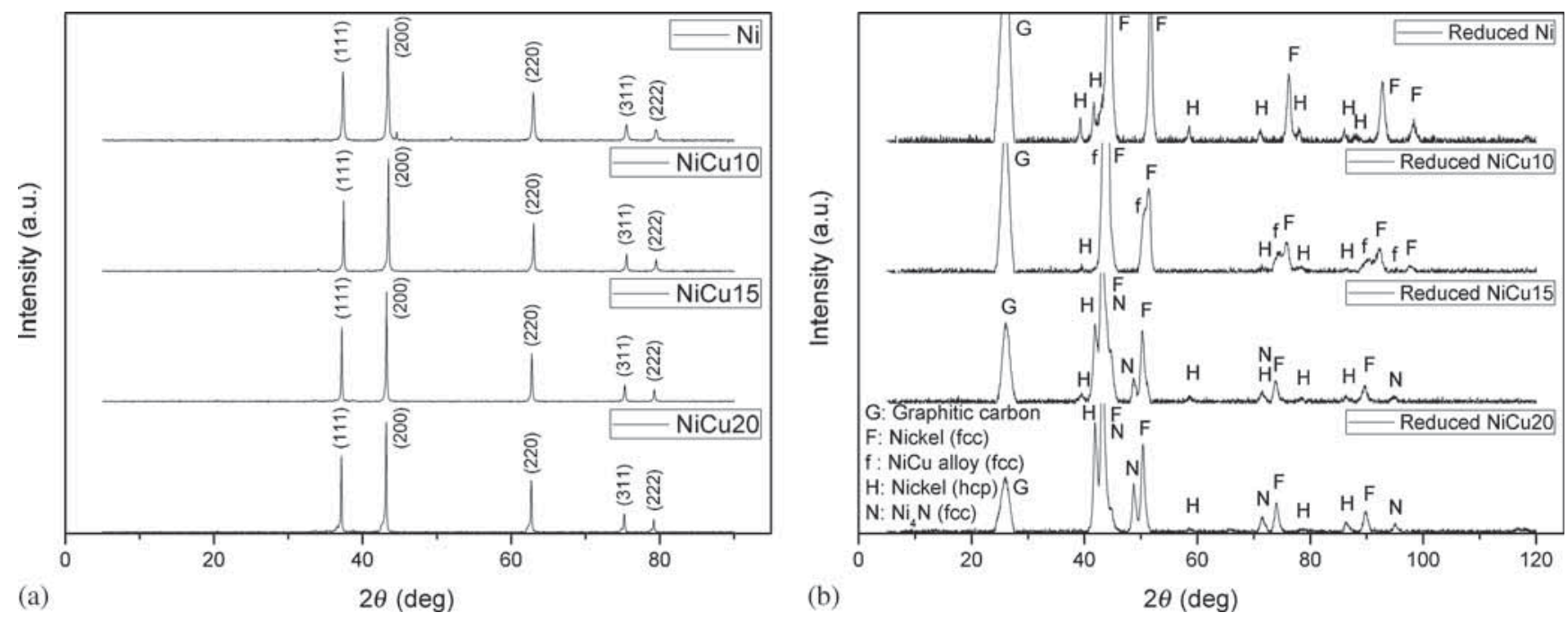

Figure 3. XRD patterns of nanoparticles obtained (a) before and (b) after exposure of nickel oxide-based particles to reducing environment similar to that prevailing during the growth of CNS. 
Table 1. Details of doping, size distribution and phases before and after growth of CNS.

\begin{tabular}{|c|c|c|c|c|c|}
\hline $\begin{array}{l}\text { Designation of } \\
\text { oxide material }\end{array}$ & $\begin{array}{l}\text { Doping level } \\
\text { (wt.\%) }\end{array}$ & $\begin{array}{l}\text { Lattice parameter }(\AA) \\
\text { for fcc phase of oxides }\end{array}$ & $\begin{array}{l}\text { Size distribution } \\
(\mathrm{nm})\end{array}$ & $\begin{array}{l}\text { Avg. size } \\
\quad(\mathrm{nm})\end{array}$ & $\begin{array}{c}\text { Reduced material } \\
\text { (crystal structure)/lattice } \\
\text { parameter }(\AA)\end{array}$ \\
\hline $\mathrm{Co}$ & 0 & 8.065 & $19-50$ & 40 & Cobalt (fcc)/3.544 \\
\hline $\mathrm{CoCu} 01$ & 01 & 8.074 & $19-45$ & 33 & Cobalt (fcc)/3.544 $\mathrm{Co}_{2} \mathrm{C}$ (orthorhombic) \\
\hline $\mathrm{CoCu} 10$ & 10 & 8.084 & $58-117$ & 71 & Cobalt (fcc)/3.544 $\mathrm{Co}_{2} \mathrm{C}$ (orthorhombic) \\
\hline $\mathrm{CoCu} 20$ & 20 & 8.084 & $20-54$ & 41 & Cobalt (fcc)/3.544 copper (fcc) \\
\hline $\mathrm{Ni}$ & 0 & 4.176 & $23-82$ & 53 & Nickel (fcc)/3.524 nickel (hcp) \\
\hline $\mathrm{NiCu} 10$ & 10 & 4.182 & $39-84$ & 60 & $\mathrm{NiCu}($ fcc)/3.540 NiCu (hcp) \\
\hline $\mathrm{NiCu} 15$ & 15 & 4.185 & $42-78$ & 66 & $\mathrm{NiCu}(\mathrm{fcc}) / 3.619 \mathrm{NiCu}(\mathrm{hcp})$ \\
\hline $\mathrm{NiCu} 20$ & 20 & 4.188 & $28-60$ & 46 & $\mathrm{NiCu}(\mathrm{fcc}) / 3.624 \mathrm{NiCu}(\mathrm{hcp})$ \\
\hline
\end{tabular}

fcc phase at room temperature, but in reduced doped oxides one observes orthorhombic $\mathrm{Co}_{2} \mathrm{C}$ phase as well along with copper, particularly at higher level of doping as indicated in table 1. Zhi and Song [25] in their study carried out at $470^{\circ} \mathrm{C}$ similarly observed presence of fcc cobalt primarily but they also observed a few weak lines of hcp cobalt. However, their inference that the growth of carbon filaments is catalysed by fcc cobalt and that successful growth depends on suppression of stable hexagonal phase appear speculative. The cubic phase of metallic cobalt has also been found to be present in the reduced oxide catalyst obtained during CNS synthesis $[26,27]$. Tyagi et al [28] have formed nano-clusters at $350^{\circ} \mathrm{C}$ under cover of ammonia using micron thick layer of cobalt and observed a mixture of fcc and hep phases of cobalt nanorods inside multiwalled carbon nanotube (MWCNT) grown over these clusters at $820^{\circ} \mathrm{C}$. Again there is another speculation that interaction between graphene and hcp crystallographic planes of cobalt favours graphitization [29]. It has been claimed that metallic cobalt crystallites of sizes larger than $40 \mathrm{~nm}$ have stable hcp phase, while those between 20 and $40 \mathrm{~nm}$ have a mixture of hcp and fcc phases, but for sizes below $20 \mathrm{~nm}$, the fcc phase is the most stable one [31]. However, the oxide nanoparticles used in our study have average sizes between 33 and $71 \mathrm{~nm}$, but we have not observed any significant presence of hcp phase in reduced metal. But the size of reduced metallic particles has not been determined in our study.

Sanjabi et al [38] used thermodynamic modelling of particle formation by reshaping of metallic catalyst nanofilm of thickness of $5 \mathrm{~nm}$ for use in growing carbon nanotube (CNT) at $700^{\circ} \mathrm{C}$ and inferred that the structure of nickel catalyst is fcc nickel while for cobalt catalyst it is hcp. Modelling in the domain of nanoparticles is extremely difficult and its prediction for cobalt catalyst does not appear to hold good. However for nickel, our study shows presence of a mixture of both fcc and hcp nickel after reduction of pure and doped oxide nanoparticles of average sizes between 46 and $66 \mathrm{~nm}$. Tyagi et al [28] found fcc nickel of size 10-15 nm inside MWCNT. Geng et al [30] have observed by highresolution transmission electron microscopy (HRTEM) that crystal fringes of nickel single crystal of the sizes between 1 and $30 \mathrm{~nm}$ encapsulated by graphene layers at $500^{\circ} \mathrm{C}$ have fringe spacing of $0.203 \mathrm{~nm}$, corresponding to (111) plane of fcc phase of nickel. At low temperatures, hcp phase of nickel has been observed to be stable, but undergoes a transition to fcc phase above $380^{\circ} \mathrm{C}$ [39]. Mi et al [40] thought that the presence of chemical entities/impurities and surface stabilization by organic molecules may be the key to formation of nanocrystalline hcp nickel. Illy et al [32] have observed sizedependent phase transition of nickel nanoparticles from fcc to hcp when the size becomes smaller than $4 \mathrm{~nm}$. Tian et al [18] have found that the nano-sized hcp nickel islands transform into normal fcc structure when the size of the islands exceeds a critical size of about $2.5 \mathrm{~nm}$ thickness and lateral size of $5 \mathrm{~nm}$.

The nanoparticles observed inside CNS grown using pure nickel oxide have been examined using TEM and the results are shown in figure 4. The EDS spectrum taken on the nanoparticle inside $\mathrm{CNS}$, figure $4 \mathrm{a}$, demonstrates the reduction of nickel oxide into nickel as shown in figure $4 \mathrm{~b}$. The particle inside CNS has size of $\sim 180 \mathrm{~nm}$ as observed under TEM shown in figure $4 \mathrm{c}$ and the selected area electron diffraction shows the presence of hcp nickel along with fcc nickel as revealed in figure $4 \mathrm{~d}$.

A limited number of experiments have been carried out at similar temperature but at different environment to examine the effect of individual constituents of incoming gas on reduction and also, the phases formed. Figure 5a shows the XRD of pure cobalt oxide $\left(\mathrm{Co}_{3} \mathrm{O}_{4}\right)$ reduced in environments of $\mathrm{C}_{2} \mathrm{H}_{2}$ and $\mathrm{NH}_{3}$ alone and compared with those in $\mathrm{C}_{2} \mathrm{H}_{2}+\mathrm{NH}_{3}$. The temperature $\left(575^{\circ} \mathrm{C}\right)$ and flow rate have been so chosen as to avoid extensive formation of CNS and ensure that diffraction response is coming primarily from the reduced oxide. It has been observed from figure 5 that ammonia alone can also reduce the oxide nanoparticles, but the rate appears to be relatively slower and so, the reduction is not yet complete in the given time at a temperature of $575^{\circ} \mathrm{C}$ as indicated by the presence of oxide peaks in XRD, although relatively weak. Chen et al [20] have shown direct experimental evidence of facile reduction of $\mathrm{Fe}_{2} \mathrm{O}_{3}$ nanoparticles located inside MWCNT only above a certain temperature $\left(600^{\circ} \mathrm{C}\right)$. In our earlier work [21] we have demonstrated that the oxide nanoparticles undergo melting/surface melting at the growth temperature of $640^{\circ} \mathrm{C}$ maintained by us in the chamber of 

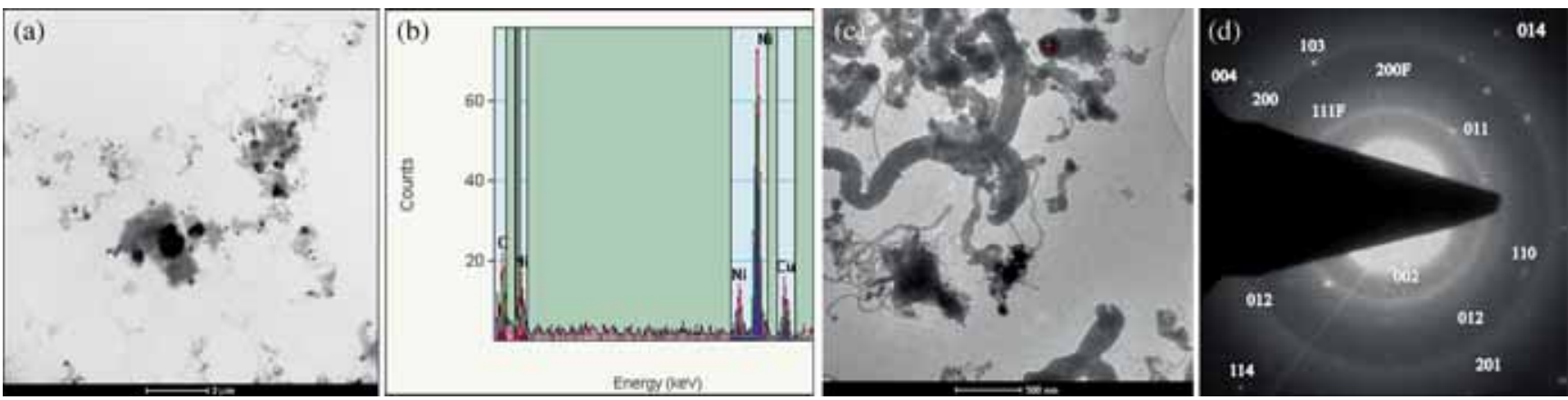

Figure 4. (a) STEM image of nanoparticles inside CNS grown using nickel oxide, (b) EDS spectrum of dark spots in a, (c) bright field TEM image of CNS containing catalyst particles, and (d) selected area diffraction (SAD) of nanoparticle inside CNS as shown by cross point in c, with spots belonging to hep (unmarked) and fcc (marked F) nickel, and rings belonging to graphitic carbon.
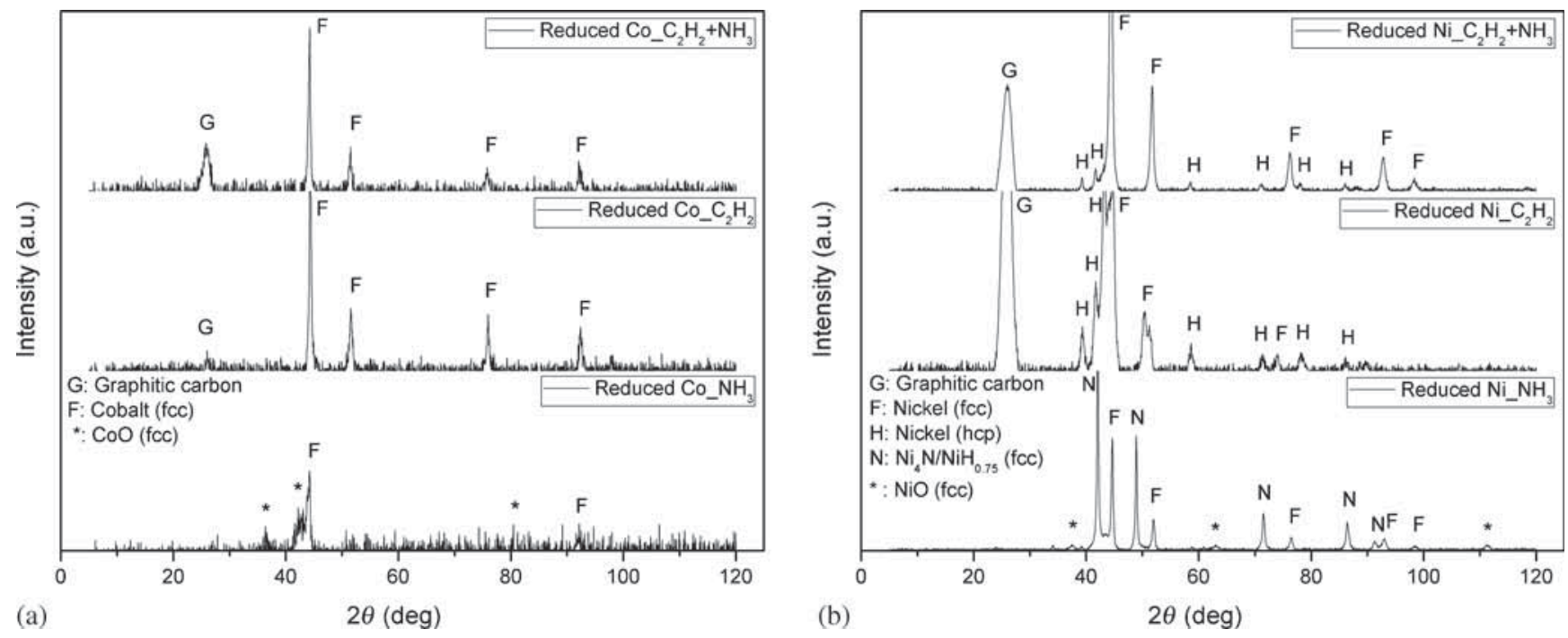

Figure 5. XRD patterns of (a) cobalt and (b) nickel nanoparticles reduced from their respective oxides in three different atmospheres.

CCVD during growth of CNS. The reduction process inside the oxide nanoparticles may take place faster through melting at the surface where diffusion of the reducing element like carbon or hydrogen will be faster. The balance between the rate of decomposition of feedstock gas and the melting of catalyst nanoparticles, both of which depend on an optimum temperature [41], may decide the extent of reduction. In all three reducing environments used in the present study, for the range of particle sizes investigated, the cobalt nanoparticles are in cubic phase which is a metastable phase for the bulk at room temperature. When pure $\mathrm{NiO}$ reduces in both $\mathrm{C}_{2} \mathrm{H}_{2}+\mathrm{NH}_{3}$ environment, it produces mainly fcc phase of nickel with some hcp phase and some graphitic carbon as can be seen from figure $5 \mathrm{~b}$, while the same material reduced under only $\mathrm{C}_{2} \mathrm{H}_{2}$ environment contains more hcp phase of nickel along with fcc phase as well. It appears that the presence of nitrogen discourages formation of hcp nickel but the presence of carbon encourages it. The presence of fcc nickel alone in the oxide reduced in $\mathrm{NH}_{3}$ gas environment strongly indicates that the other elements present along with the reducing element influence stability of phases in the reduced oxide particles as inferred.

The solubility of copper and the resulting structure of the phases present in the reduced oxide nanoparticles may depend on the size. The nanoparticles inside CNS grown using oxide designated as $\mathrm{NiCu} 10$ have been examined by TEM and HRTEM, and the results are shown in figure 6 . Although the average size of the particles of the material designated as $\mathrm{NiCu} 10$ is in the range of few tens of $\mathrm{nm}$, the reduced particles observed inside CNS have large variation of size from about 3 to $200 \mathrm{~nm}$ as shown in figures $6 \mathrm{a}$ and $\mathrm{b}$ under TEM and figures $6 \mathrm{c}$ and $\mathrm{d}$ under HRTEM. The HRTEM image in figure 6e reveals that the lattice spacing $(\sim 0.219 \mathrm{~nm})$ of the nanoparticle examined matches with (002) planes of hcp nickel. So the mixture of phases observed in the catalysts could be due to nanoparticles of different sizes present.

In our earlier work, we emphasized the role of melting/surface melting of oxide nanoparticles depending on their size and the extent of doping, and also, their reduction 

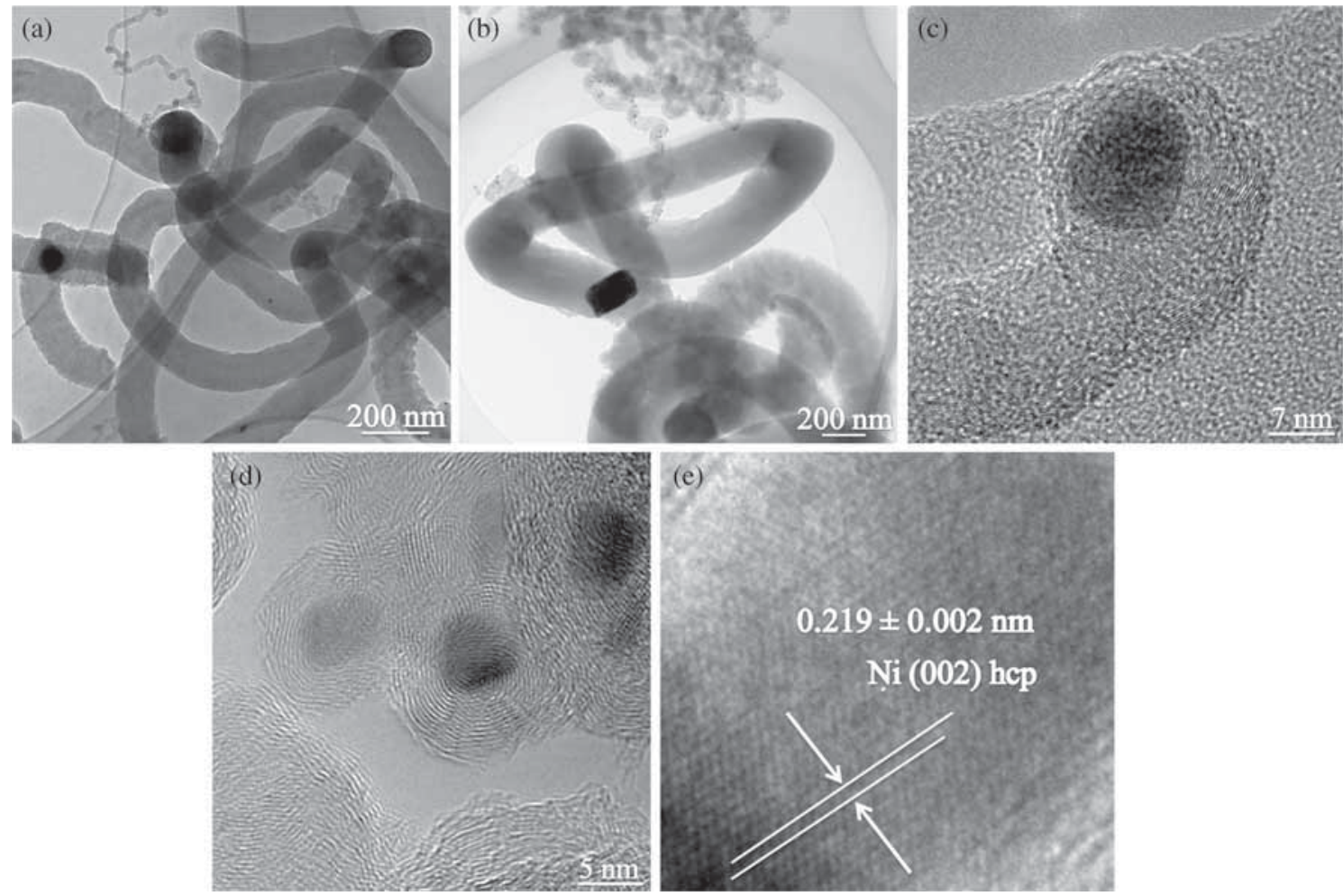

Figure 6. (a-e) Typical TEM and HRTEM images of the nanoparticles inside CNS grown using nanoparticles of oxide $(\mathrm{NiCu} 10)$.

in the context of growth of CNS [21]. However, the structure of the reduced metal may be relevant in determining the extent of melting of the reduced metal nanoparticles, and the vapour-liquid-solid mechanism of growth of CNS requires the presence of molten phase $\mathrm{L}$ to facilitate rapid growth as commonly observed, although difference in melting point of nanostructures may not be very large as evident from occurrence of these structures as commonly occurring defect structure in the bulk. The structure, however, will also be important if the reduced nanoparticles of metals act as template for the nucleation of CNS, as it is often assumed in simulation studies. However, the present authors have argued against such an effect and inferred that the role of the metallic catalyst is limited to occupying the open-end positions of the CNT to prevent closure by formation of spherical cap as observed in $\mathrm{C}_{70}$ nanostructures to allow further cylindrical growth $[24,42]$.

The plausible steps involved towards the reduction of nanoparticles of oxide under conditions existing in the present study are (i) melting of oxide nanoparticles, (ii) decomposition of gases leading to reducing species like carbon and hydrogen, (iii) reduction of surface layer of the melt and (iv) diffusion of the reducing species inside the molten layer to continue reduction reaction inside the particle. Hydrogen is of very small size and may have high diffusion coefficient even in solid oxides. Thus, solid-state reduction of oxide nanoparticles by hydrogen may also take place without melting, but melting will surely accelerate diffusion even for hydrogen reduction. The doping could be effective tool to tailor the catalyst properties $[43,44]$, and may change the extent of diffusion and could influence the kinetics of reduction in oxides [45]. The equilibrium structure of the reduced metal nanoparticle on solidification could be different from that of bulk, since the atom positions corresponding to lowest energy deviate from the positions in the bulk and so a different structure may become stable for nanoparticles. The influence of gaseous species in the environment as indicated in the results may have interesting influence on the structure of reduced metal in the nanoparticles.

\section{Conclusions}

The present study involving chemical nature and phases of reduced oxide nanoparticles of cobalt and nickel, undoped and doped with copper oxide, has led to the following conclusions:

(a) The oxide nanoparticles of nickel and cobalt, either doped by copper oxide or without doping, get reduced in gaseous environments of $\mathrm{C}_{2} \mathrm{H}_{2}+\mathrm{NH}_{3}, \mathrm{C}_{2} \mathrm{H}_{2}$ and $\mathrm{NH}_{3}$ at $575^{\circ} \mathrm{C}$. However, the rate of reduction of cobalt oxide in $\mathrm{NH}_{3}$ is slower than that in $\mathrm{C}_{2} \mathrm{H}_{2}$.

(b) The nanoparticles of cobalt reduced from either doped or undoped oxide has fcc structure, which is the defect structure normally present in the bulk cobalt. 
(c) At lower level of doping of cobalt oxide below $10 \mathrm{wt} . \%$, there is formation of cobalt carbide, in environment of $\mathrm{C}_{2} \mathrm{H}_{2}+\mathrm{NH}_{3}$, but carbide is not present in reduced pure cobalt oxide. However, carbide formation gets suppressed at higher level of doping of 20 wt.\% when separate phase of metallic copper makes its appearance.

(d) The nanoparticles of nickel reduced from either doped or undoped oxide in environment of $\mathrm{C}_{2} \mathrm{H}_{2}+\mathrm{NH}_{3}$ have mixed phases having both fcc and hep structures, which are respectively the equilibrium and defect structure commonly present in bulk nickel. The lattice parameter of fcc structure reduced from doped nickel oxide increases with increase in doping, indicating that it is possibly $\mathrm{Ni}-\mathrm{Cu}$ alloy.

(e) It appears that the presence of nitrogen and hydrogen discourage the formation of hep nickel as observed in nickel oxide reduced in the environment of $\mathrm{NH}_{3}$.

\section{Acknowledgements}

We gratefully acknowledge the support provided for this study under Indo-Australia Strategic Research Fund (IASRF) of the Department of Science and Technology (DST), Government of India, for carrying out part of this work in the University of Queensland.

\section{References}

[1] Dupuis A C 2005 Prog. Mater. Sci. 50929

[2] Baker R T K, Alonzo J R, Dumesic J A and Yates D J C 1982 J. Catal. 7774

[3] Rummeli M H, Kramberger C, Gruneis A, Ayala P, Gemming T, Buchner B and Pichler T 2007 Chem. Mater. 194105

[4] Hofmann S, Blume R, Wirth C T, Cantoro M, Sharma R, Ducati C, Havecker M, Zafeiratos S, Schnoerch P, Oestereich A, Teschner D, Albrecht M, Knop-Gericke A, Schlogl R and Robertson J 2009 J. Phys. Chem. C 1131648

[5] Amama P B, Zemlyanov D, Sundarakannan B, Katiyar R S and Fisher T S 2008 J. Phys. D: Appl. Phys. 41165306

[6] Jeangros Q, Hansen T W, Wagner J B, Damsgaard C D, Dunin-Borkowski R E, Hebert C, Van Herle H and HesslerWyser A 2013 J. Mater. Sci. 482893

[7] Richardson J T, Scates R and Twigg M V 2003 Appl. Catal. A 246137

[8] Furstenau R P, McDougall G and Langell M A 1985 Surf. Sci. 15055

[9] Hernadi K, Fonseca A, Nagy J B, Bernaerts D and Lucay A A 1996 Carbon 341249

[10] Nishimura K, Okazaki N, Pan L and Nakayama Y 2004 Jpn. J. Appl. Phys. 43 L471

[11] Yoshida H, Takeda S, Uchiyama T, Kohno H and Homma Y 2008 Nano Lett. 82082

[12] Ni L, Kuroda K, Zhou L P, Ohta K, Matsuishi K and Nakamura J 2009 Carbon 473054

[13] Hoch M 1988 Calphad 1283
[14] Yazyev O V and Pasquarello A 2008 Phys. Rev. Lett. 100 156102

[15] Yang R, Goethel P, Schwartz J and Lund C 1990 J. Catal. 122 206

[16] Wirth C T, Hofmann S and Robertson J 2009 Diamond Rel. Mater. 18940

[17] Sharma R, Moore E S and Rez P 2009 Nano Lett. 9689

[18] Tian W, Sun H P, Pan X Q, Yu J H, Yeadon M, Boothroyd C B, Feng Y P, Lukaszew R A and Clarke R 2005 Appl. Phys. Lett. 86 131915-1

[19] Pearson W B 1958 A handbook of lattice spacings and structures of metal and alloys (London: Pergamon Press)

[20] Chen W, Pan X, Willinger M G, Su D S and Bao X 2006 J. Am. Chem. Soc. 1283136

[21] Jana M, Sil A and Ray S 2011 Carbon 495142

[22] Sharma R, Chee S W, Herzing A, Miranda R and Rez P 2011 Nano Lett. 112464

[23] Takagi D, Homma Y, Hibino H, Suzuki S and Kobayashi Y 2006 Nano Lett. 62642

[24] Jana M, Sil A and Ray S 2014 Appl. Phys. A 1171425

[25] Zhi L and Song H H 2003 Intl. J. Nanosci. 21

[26] Liu S, Zhu J, Mastai Y, Felner I and Gedanken A 2000 Chem. Mat. 122205

[27] Rana R K, Koltypin Y and Gedanken A 2001 Chem. Phys. Lett. 344256

[28] Tyagi P K, Misra A, Singh M K, Misra D S, Ghatak J, Satyam P V and Normand F L 2005 Appl. Phys. Lett. 86 253110-1

[29] Shibuta Y and Elliott J A 2009 Chem. Phys. Lett. 472200

[30] Geng J, Li H, Golovko V B, Shephard D S, Jefferson D A, Johnson Brian F G, Hofmann S, Kleinsorge B, Robertson J and Ducati C 2004 J. Phys. Chem. B 10818446

[31] Kitakami O, Sato H, Shimada Y, Sato F and Tanaka M 1997 Phys Rev. B: Cond. Mat. 5613849

[32] Illy S, Tillement O, Machizaud F, Dubois J M, Massicot F, Fort Y and Ghanbaja J 1999 Philos. Mag. 791021

[33] Strauss B, Frey F, Petry W, Trampenau J, Nicolaus K, Shapiro S M and Bossy J 1996 Phys. Rev. B 546035

[34] Nishizawa T and Ishida K 1984 Bull. Alloy Phase Diagrams 5161

[35] Ouyang G, Tan X, Wang C X and Yang G W 2006 Nanotech. 174257

[36] Straumal B B, Mazilkin A A, Protasova S G, Myatiev A A, Straumal P B and Baretzky B 2008 Acta Mater. 566246

[37] Homma Y, Liu H, Takagi D and Kobayashi Y 2009 Nano Res. 2793

[38] Sanjabi S and Bayat N 2012 Modelling Simul. Mater. Sci. Eng. 20035002

[39] Carturan G, Cocco G, Enzo S, Ganzerla R and Lenarda M 1988 Mater. Lett. 747

[40] Mi Y, Yuan D, Liu Y, Zhang J and Xiao Y 2005 Mater. Chem. Phys. 89359

[41] Saeidi M and Vaezzadeh M 2009 Physica E 411723

[42] Ghosh K, Kumar M, Maruyama T and Ando Y 2009 Carbon 471565

[43] Wang H, Li Z, Ghosh K, Maruyama T, Inoue S and Ando Y 2010 Carbon 482882

[44] Wang H, Ghosh K, Li Z, Maruyama T, Inoue S and Ando Y 2009 J. Phys. Chem. C 11312079

[45] Parravano G 1952 J. Am. Chem. Soc. 741194 